\title{
Amiloidose Manifestando-se com Pseudo-Hipertrofia Muscular
}

\section{Amyloidosis Presenting as Muscle Pseudohypertrophy}

\author{
Rodrigo Bortoli(1), Isabella Vargas de Souza Lima(2), Aristides Cheto Queiroz ${ }^{(3)}$, \\ Mittermayer Barreto Santiago ${ }^{(4)}$
}

\section{RESUMO}

Amiloidose tipo ALé uma doença rara causada pela deposição extracelular de fragmentos de cadeias leves monoclonais em órgãos e tecidos. Pode apresentar-se com uma ampla variedade de sinais e sintomas, e o acometimento cutâneo-muscular, simulando pseudo-hipertrofia muscular, é um achado muito raro. São descritos dois casos que apresentaram tal manifestação. Caso 1 -Mulher, 61 anos, há quatro meses com história de mialgia e aumento da massa muscular nas cinturas pélvica, escapular e região cervical. Não havia alterações significativas ao exame físico, exceto aparente hipertrofia muscular difusa e discreta macroglossia. Caso 2 - Homem, 51 anos, há dois anos com cansaço e espessamento cutâneo progressivo do dorso, pescoço e braços. Em outros serviços levantou suspeitas diagnósticas de esclerodermia ou de escleredema de Buschke; desde fevereiro de 2007 passou a ser acompanhado nesse serviço e referia, havia cerca de um ano, disfagia para sólidos, disartria e dificuldade para movimentar a língua. Chamava atenção em seu exame o porte físico atlético com musculatura torácica proeminente, porém referia não fazer exercícios físicos. Em ambos os casos, a biópsia cutânea foi realizada com identificação do depósito amilóide por meio da coloração de vermelho congo.

Palavras-chave: amiloidose, pseudo-hipertrofia muscular.

\section{INTRODUÇÃO}

A amiloidose constitui um grupo heterogêneo de doenças, de ocorrência rara, caracterizado pelo depósito extracelular da proteína amilóide, composta por: proteína fibrilar, glicosaminoglicano e componente $\mathrm{P}$ (nãofibrilar). A proteína amilóide apresenta as características de insolubilidade, resistência à proteólise e afinidade pela coloração do vermelho Congo. A classificação mais atual da amiloidose baseia-se nas diferentes proteínas fibrilares e, conseqüentemente, em seus diferentes precursores ${ }^{(1)}$.

\begin{abstract}
AL amyloidosis is a rare disease secondary to extracellular deposition of light chains fragments in organs and tissues. It can cause a wide variety of signs and symptoms, being the muscular pseudohypertrophy form a very rare finding. Case 1 - a 61 -yearold female had a history of myalgia and increase of muscular mass on pelvic and scapular girdle and cervical region. Besides the generalized muscular hypertrophy and discrete macroglossia, the rest of physical examination was normal. Case 2 - a 51-year-old male complained of tiredness and progressive cutaneous thickening on his thorax, neck and arms for the last two years. Initially, he was misdiagnosed with either scleredema of Buschke or scleroderma. In February 2007 he was referred to our service, reporting symptoms of dysphagia and difficulty to move his tongue. On physical examination, besides the skin thickness, there was an evident muscle hypertrophy out of proportion the reported exercise practice. In both cases, subcutaneous biopsy was undertaken which revealed amyloid deposit by congo red dye.
\end{abstract}

Keywords: amyloidosis, muscular pseudohypertrophy.

A forma primária apresenta a proteína fibrilar AL, cujos precursores são imunoglobulinas de cadeia leve: $\kappa$ e $\lambda^{(2)}$. Clinicamente, pode apresentar-se com ampla variedade de sinais e sintomas, dependendo dos órgãos acometidos, sendo mais comumente evidenciados proteinúria nefrótica, hepatoesplenomegalia, insuficiência cardíaca congestiva, síndrome do túnel do carpo e macroglossia ${ }^{(3,4)}$.

O acometimento cutâneo-muscular simulando pseudohipertrofia muscular é um achado ainda mais raro ${ }^{(5,6,7)}$. Descrevemos dois casos de amiloidose apresentando quadros semelhantes de pseudo-hipertrofia muscular.

Recebido em 19/04/07. Aprovado, após revisão, em 05/06/07. Declaramos a inexistência de conflitos de interesse.

1. Ex-residente do Serviço de Reumatologia do Hospital Santa Izabel (HSI)

2. Reumatologista no Serviço de Reumatologia do HSI.

3. Chefe do Serviço de Patologia do HSI.

4. Chefe do Serviço de Reumatologia do HSI, professor adjunto da Escola Bahiana de Medicina e Saúde Pública, Salvador, Bahia

Endereço para correspondência: Mittermayer B. Santiago, Praça Conselheiro Almeida Couto, 500, Nazaré, BA CEP 40000-000, Salvador, Bahia, e-mail: mitter@svn.com.br 


\section{RELATO DOS CASOS}

\section{CASO 1}

Mulher, 61 anos, com história de mialgia e aumento da massa muscular nas cinturas pélvica, escapular e região cervical, que vinham evoluindo há quatro meses. Também apresentava disfagia progressiva e perda de três quilos desde o início dos sintomas. Fazia tratamento para hipertensão com captopril e usava alendronato diariamente para osteoporose. Relatava antecedente de doença renal, que não sabia especificar e para a qual não fazia tratamento; negava artrite. Ao exame físico apresentava pressão arterial $140 \mathrm{mmHg}$ x $80 \mathrm{mmHg}$ e não havia outras alterações exceto aparente hipertrofia muscular difusa (Figura 1) e discreta macroglossia. Dentre os exames laboratoriais, hemograma, VHS, glicemia, transaminases, CK, FAN, eletroforese de proteínas séricas, testes de função tireoidiana e de função renal foram normais. Sumário de urina revelou moderada proteinúria, que foi confirmada pela presença de $2.900 \mathrm{mg}$ de proteínas em urina de 24 horas. Ultra-sonografia abdominal demonstrou rins de tamanho aumentado e ecocardiograma revelou discreta hipertrofia ventricular esquerda. O diagnóstico foi confirmado pela coloração da biópsia da gordura abdominal com vermelho congo (Figura 2). A paciente teve morte súbita, quando ainda na enfermaria em programação para a realização de gastrostomia, a qual atribuímos ao comprometimento cardíaco pela amiloidose.

\section{CASO 2}

Homem, 51 anos, iniciou cansaço e espessamento cutâneo progressivo do dorso, pescoço e braços havia dois anos, quando foram levantadas as suspeitas diagnósticas de esclerose sistêmica ou escleredema de Buschke e iniciado o tratamento com corticosteróides e azatioprina, sem melhora. Em fevereiro de 2007, passou a ser acompanhado no Hospital Santa Izabel, quando relatou disfagia para sólidos, disartria e dificuldade para movimentar a língua há um ano. Negava Raynaud e dispnéia. Exames recentes de tomografia de tórax de alta resolução e espirometria foram normais. Ao exame: PA $120 \mathrm{mmHg}$ x $80 \mathrm{mmHg}$, ausculta cardíaca, respiratória e exame abdominal normais. Aparentava porte físico atlético com musculatura torácica proeminente (Figura 3 ), porém referia não fazer exercícios físicos e não realizar esforços no trabalho (eletricista). Foi constatado espessamento cutâneo nas regiões cervical posterior e perioral, da face, do pescoço, do tórax, do ombro

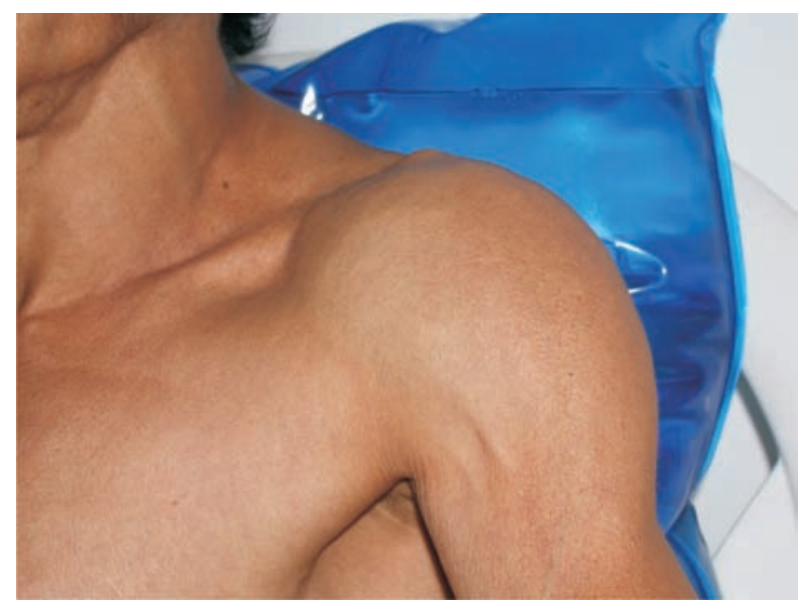

Figura 1 - Pseudo-hipertrofia de musculatura de ombros em virtude de amiloidose.

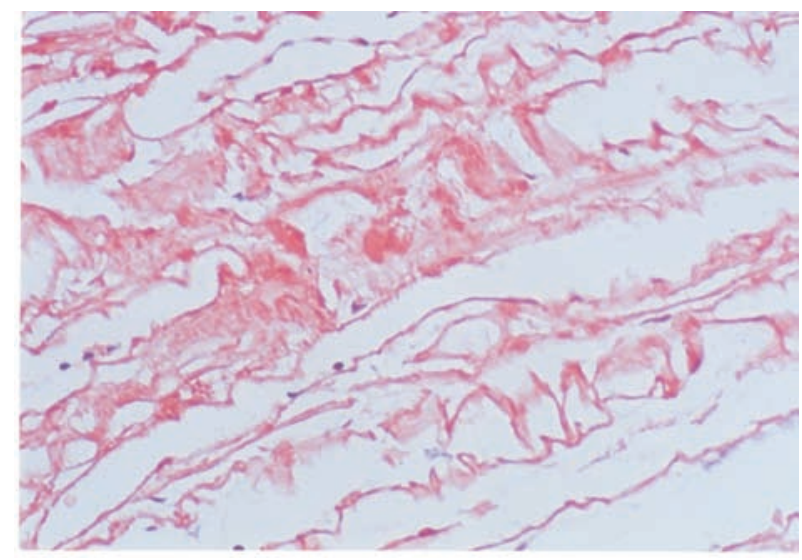

Figura 2 - Corte de tecido conjuntivo submetido às colorações habituais de hematoxilina-eosina e posterior coloração pelo vermelho congo. Demonstra-se depósito de material hialino eosinofílico, acelular, determinando espessamento da derme. Depósitos de material amilóide demonstrado pela positividade com a coloração do vermelho congo (birrefringência à luz polarizada). X 200.

e dos braços; sua língua estava enrijecida e não conseguia exteriorizá-la; hemograma, VHS, FAN, CK, eletroforese e imunoeletroforese de proteínas séricas, sumário de urina, função renal, tireoidiana e hepática estavam normais. Ecocardiograma normal; avaliação esofágica com pequena hérnia hiatal e esofagite grau leve; avaliação da deglutição revelou alteração na fase oral em virtude de déficit de movimentação da língua; diagnóstico foi obtido por meio da biópsia de pele e do tecido subcutâneo da região cervical que apresentou birrefringência positiva à luz polarizada, na coloração com vermelho congo. No momento, o paciente está em programação para transplante de medula óssea. 


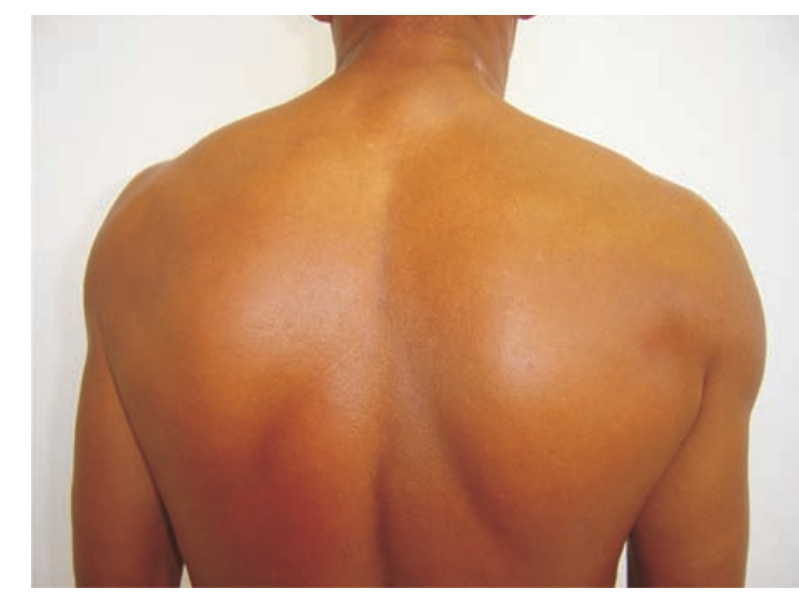

Figura 3 - Pseudo-hipertrofia muscular em dorso em virtude de amiloidose.

\section{DISCUSSÃO}

Os casos descritos chamam a atenção para a apresentação incomum da amiloidose como pseudo-hipertrofia muscular, achado fundamental para o diagnóstico de ambos os casos. Embora a eletroforese de proteínas séricas em ambos os casos não tenha demonstrado a presença de um pico monoclonal e a imunoeletroforese de proteínas no caso 2 não tenha revelado um componente de monoclonalidade (tal exame não foi realizado no caso 1 ), acreditamos que tais pacientes ilustram a forma AL de amiloidose, uma vez que a presença de componente monoclonal no soro não é universalmente vista nessa condição e a pseudo-hipertrofia muscular não tem sido descrita em outras formas de amiloidose.

Scola et al. ${ }^{(2)}$, em 2001, descreveram um caso de pseudohipertrofia muscular secundária à amiloidose e relataram

\section{REFERÊNCIAS}

1. Merlini G, Bellotti V: Molecular Mechanisms of Amyloidosis. N Engl J Med 349: 583-96, 2003.

2. Scola RH, Werneck LC, Ramos CS, Pasquini R, Graf H, Arruda WO: Amyloidotic muscle pseudohypertrofy: Case Report. Arq Neuropsiquiatr 59(A-3): 582-6, 2001.

3. Kyle RA, Greipp PR: Amyloidosis (AL). Clinical and laboratory features in 229 cases. Mayo Clin Proc 58(10): 665-83, 1983.

4. Kyle RA: Amyloidosis: a convoluted story. Br J Haematol 114(3): 529-38, 2001.

5. Lawson TM, Bevan MA, Williams BD: Clinical images: Skeletal muscle pseudo-hypertrophy in myeloma-associated amyloidosis. Arthritis Rheum 46(8): 2251, 2002. a existência de dez casos anteriormente publicados, nos quais também foram descritos os achados de macroglossia, disartria e fraqueza, além da pseudo-hipertrofia. Os autores mencionados chamaram a atenção para a presença de cardiomiopatia - à semelhança do caso 1 , embora ausente no caso 2 - como sintoma presente na paciente relatada e que não havia sido observada nos casos anteriores. A paciente 1 apresentou morte súbita ainda na enfermaria, sendo posteriormente atribuída a seu envolvimento cardíaco.

$\mathrm{O}$ aspecto muscular de pseudo-hipertrofia é decorrente da deposição de proteínas amilóides no tecido muscular esquelético, o que acaba por diminuir a elasticidade e aumentar a pressão tecidual intramuscular, reduzindo sua perfusão, o que pode contribuir para o quadro de fraqueza ${ }^{(7)}$. Infelizmente, nos dois casos aqui relatados não foi realizada biópsia de músculo uma vez que o estudo anatomopatológico de pele e tecido celular subcutâneo já demonstrava a presença do amilóide. O diagnóstico precoce com a identificação da proteína amilóide são fatores que contribuem para o prognóstico do paciente, uma vez que evita medidas terapêuticas inadequadas, como no caso 2 , e permite a introdução de condutas de suporte adequadas. Adicionalmente, a melhor compreensão da fisiopatologia e das diversas apresentações clínicas tem possibilitado o acesso dos pacientes a novos esquemas terapêuticos, como o transplante autólogo de células-tronco ${ }^{(8)}$. Enquanto no caso 1 não houve tempo suficiente para a realização de nenhuma intervenção terapêutica, o paciente do caso 2 está sendo preparado para o transplante autólogo de células-tronco, considerado hoje, em associação com altas doses de melfalam, a melhor opção para o tratamento da amiloidose de cadeia leve.

6. Windhagen A, Bufler J, Neudecker S: Gross muscle pseudohypertrophy in myeloma-associated light chain amyloidosis. Neurology 65(10): 1670, 2005.

7. Komiyama A, Kijima M, Takahashi M, Ishida S: Amyloid associated muscle pseudohypertrophy: amelioration of motor dysfunction with plasmapheresis and dimethylsulphoxide. J Neurol Neurosurg Psychiatr 60: 591-2, 1996.

8. Paladini G, Perfetti V, Merlini G: Therapy and management of Systemic AL (primary) Amyloidosis. Swiss Med WKLY 136: 715-20, 2006. 